Late Secondary Stage.

The number of cases treated in the late secondary stage is 32. Each of these had been refractory to previous treat ment with mercury. They presented severe lesions of the skin and mucous membranes-for example, deep ulcers involving the subcutaneous tissues, and extensive necrosis of tonsils, soft palate, and turbinate bones. In every case salvarsan produced complete arrest and healing of the local condition. As regards the method of treatment, 7 received subcutaneous injections of neutral suspension in the first instance, and 6 of these received an intravenous injection subsequently. The remaining 25 were each treated by two intravenous injections. In 18 out of the 32 cases the serum reaction was negative one to three months after the second injection; in 6 cases the reaction was still positive three months after the second injection; in the remaining cases the time which has elapsed since treatment is too short to admit of any conclusion.

A woman with secondary syphilis and in the sixth month of pregnancy was treated with 0.4 gram intravenously, repeated after five weeks. A healthy child was born at full time, and six months after the birth both mother and child were in good health.

\section{Tertiary Stage.}

The number of cases treated in the tertiary stage is 14 , including gummata, indolent ulcers, periosteal thickenings, and severe forms of neuralgia. The gummata disappeared and the ulcers healed in every instance. One case of severe trigeminal neuralgia in a woman who had never had any symptoms of syphilis, but whose serum gave a positive reaction, was cured after an intramuscular injection of 0.5 gram in clear alkaline solution. Severe neuralgic pains in the legs in two syphilitics, twenty years aiter infection, disappeared after one intravenous injection of 0.4 gram in each case.

Late Nervous Disorders.

The number of cases of general paralysis of the insane treated is 58 . In 12 patients there has been a marked amelioration of symptoms, and 6 of these are now free from restraint and pursuing their ordinary work. In addition, 7 cases of locomotor ataxy have been treated. In 3 there has been marked improvement. It must be noted, however, that while distinct benefit has been obtained in "parasyphilitic" conditions, the results are much inferior to those in the more recent manifestations.

\section{Congenital Syphilis.}

Three cases of congenital syphilis with late lesions have been treated. Here also the results are less satisfactory than in recent acquired syphilis. The symptoms in such cases disappear slowly, and the serum reaction tends to remain positive. One case of an extensive skin syphilide in a boy of 15 healed excellently, and the serum reaction became negative after one subcutaneous injection ( 0.45 gram, which was poorly absorbed) and two intravenous injections (0.2 and 0.27 gram).

\section{Advantages and Risks of Salvarsan.}

The effect of the injection is, in most instances, im mediate, and intravenous administration causes practically no discomfort. One injection is more efficacious than a prolonged course of mercury. Symptoms dis appear and ulcers heal rapidly; not merely does this diminish chances of spreading infection, but it saves the patient from the grave consequences of chronic lesions Cases which have proved refractory to mercury generally yield at once to salvarsan. By intravenous injection the drug is brought into contact with the tissues in maximum concentration; hence the conditions are most favourable for sterilization.

We have given about 400 intravenous injections, and have observed no serious result. The only case showing severe symptoms was that of a man who was seized a few hours after the second injection with severe sickness and vorniting, accompanied by considerable collapse. On the following day jaundice was present. In three days the symptoms had passed off. The first injection had been well borne in this case. A complication which may follow the subcutaneous administration of neutral suspension is the occurrence of extensive necrosis of the skin and the adjacent tissue. Hence this method of injection cannot be recommended. An examination of the literature shows that in most instances fatal results occurred in cases which were in a hopeless condition prior to treatment, or in which the drug had been wrongly administered. Taking into consideration also the fact that salvarsan, as we have been informed by Messrs. Meister, Lucius, and Brüning, has been administered about a million times during the first year of its use, we consider that the unfavourable criticisms regarding the toxicity of the drug are witbout foundation. This applies to statements regarding danger both of death and also of nerve damage following treatment with salvarsan. The drug compares favourably with cocaine and antipyrin as regards safety of administra. tion, and it is probably safer than ether or chloroform.

\section{Method of Treatment.}

Much light has recently been thrown on the latency and chronicity of syphilitic infections. It is probable that mercury, especially as ordinarily administered by the mouth, in the majority of cases renders the infection merely latent, so that there is still the possibility of manifestations of the disease occurring at a later date. The object of treatment is to produce complete sterilization. We would recommend as the best possible means to this end a combined therapy. The treatment should be begun as soon as possible. Where there is the suggestion of a primary syphilitic lesion, even if spirochaetes cannot be found and the serum reaction is negative, treatment should be begun without delay. An intravenous injection of alkaline solution of salvarsan should be given ( 0.4 to 0.5 gram in the case of a man), and this should be repeated in three weeks. After each injection a course of mercurial inunction should be given. Of course, attention should be paid to general hygiene, and there should be abstention from tobacco and alcohol.

The serum test is indispensable for controlling the effect of treatment. It is not enough that the serum should be negative on one occasion; it must remain negative. As the result of inefficient treatment the serum may become negative only temporarily. An examination of the serum should be made at periods of three to six months, and again a year after all symptoms have disappeared. It cannot be too strongly emphasized that the syphilis reaction must be carried out by those experienced in the use of a reliable method; abbreviated and simplified tests are likely only to prove misleading. Thus, in our experience there is no method so delicate and so uniformly reliable as that involving the use of lecithin and cholesterin, which has been described by Dr. Cruickshank and ourselves.

\section{SALVARSAN IN LEPROSY.}

F. A. DE VERTEUIL, M.R.C.S.ENG., MEDICAL SUPERINTENDENT, LEPER ASYLUM, COCORITE, TRINIDAD, AND

\section{F. L. DE VERTEUIL, M.D.EdIN., M.R.C.S.ENG.,} L.R.C.P.LOND., SURGEON, R.N. (RET.).

ARsEnIC in its various forms is a drug that has often been employed in the treatment of leprosy, but it has had little or no influence in arresting the slow but steady progress of the malady. A few cases have, however, been recorded in which it apparently gave satisfactory results. We ourselves have tried in a few selected cases injections of sodium cacodylate and atoxyl. The beneficial results obtained in these cases made us anxious to try salvarsan (dioxy-diamido-arsenobenzol).

The opportunity was afforded by the arrival at Trinidad in December, 1910, of Dr. Rost, of the German cruiser Freya, who had a number of tubes of the preparation which had been given to him at Kiel for trial in tropical diseases. He kindly placed some of these at our disposal, came himself to the asylum, and instructed us in the technique of injection.* Wechselmann's method ${ }^{1}$ was used, the powder being ground in a sterile mortar into which about 6 to $7 \mathrm{c} . \mathrm{cm}$. of sterile oleum olivarum was gradually poured, and thoroughly rubbed under slight pressure until a fine emulsion was obtained. The needle used for the injection was of rather wide calibre. The preparation of the * During lris stay in Triaidad Dr. Rost, on the advice of one of us, also injected cases of yôws at the St. Augustine Hospital. The wonderful results obtained in these cases have been recently puhlished by Dr. Alston (BRTTISH MEDICAI JOURNAL, February 18th and March
18th, 1910). 
emulsion took only from three to four minutes, and solution, neutralization, etc., was dispensed with. The injections were made intramuscularly into the buttocks. The patients were then kept in bed for forty-eight hours. The pain caused by the injection varied in individual cases, but was not any greater than the pain experienced in an intramuscular injection of mercury. All the patients, however, complained of intense pain, usually shooting down the leg, beginning from six to twelve hours after injection and lasting from twenty-four to forty-eight hours. This pain often prevented sleep. In three cases of syphilis which one of us subsequently injected by the same method, the pain was so severe that morphine had to be exhibited. In another case of syphilis a sterile necrotic abscess formed at the site of injection. On opening the abscess about three weeks later, some small yellow particles of salvarsan could still be seen. In none of the cases of leprosy was there any abscess formation, but a hard, somewhat sensitive lump could be felt for several weeks after. There was usually a rise of $1^{\circ}$ to $2^{\circ}$ in temperature.

In .all, 9 cases of leprosy were injected -8 tubercular and 1 anaesthetic. Three of the cases were very advanced cases of tubercular leprosy with marked leonine feature. It was rather unfortunate that these cases were chosen, as no result could reasonably be expected.

The cases were injected on January 5th. The three cases referred to above showed no change apart from some slight bacteriolysis of the bacilli taken from beneath the dermis. No observation could be made on one of the patients, as he ran away from the asylum shortly afterwards. The remaining five patients showed some signs of clinical improvement, manifested chiefly in a sense of iinproved physical well-being, keener appetite, and more energy for work, though there was little change to be noticed in the outward signs of the disease. The patients felt so much better that four of their number were extremely anxious to have a second injection. The fifth declined on account of the pain. A second injection was accordingly given to these four patients on February 5th. 'T'wo months later there was little change to be noticed in the outward appearance of three of the cases, though in all there seemed to have been some slight diminution in the size and some softening of the leprous nodules. In the fourth, the anaesthetic case, a large dark macula spot in the abdomen had become much lighter three weeks later, and at the time of this observation, two months later, had almost disappeared.

Though there was little change to be noticed in the outward manifestations of the disease, there was some noteworthy differences in the appearance of microscopic slides taken before and after injection. The preparations were made from scrapings taken beneath the dermis over leprotic nodules. In all the tubercular cases the bacilli were still plentiful; in the anaesthetic case, however, there was a noticeable reduction in their number.

The chief change, present more or less in all the cases, was in the appearance of the bacilli. They had become granular, with coccothrix-like distribution, many being clumped together in granular-like masses. In other cases granules in large numbers were to be seen scattered all over the field. This bacteriolytic change was very pronounced in a few cases - in the anaesthetic case especially, in which it was much more extensive than we have ever seen it, even in cases which have been showing improvement under nastin treatment. The bacteriolysis or degenerative process became most marked about fourteen days after injection. These results agree very closely with those reported by Ehlers ${ }^{2}$ from Iceland, where Bjarulyédinsson injected seven cases with tubes supplied to him by Ehrlich.

We would suggest to those who desire to try the drug in this disease that injections should be given every three to four weeks. Early cases should, as much as possible, be selected; Dr. Rost had some hesitation in choosing an anaesthetic or nervous case. To judge, however, from the case selected, we do not think there is any danger in injecting an anaesthetic case, provided, of course, there are no eye symptoms and the kidneys are not diseased.

1 Simple Method of Injection of the Ehrlich-Hata Preparation, by R. Volk (Wein. med. Klin., No. 35, 1910), quoted by BRITISH MEDICA

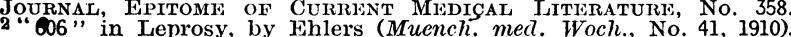
quoted by BRITISH MEDICAL JoURNAL, EPITOME OF CURRENT MEDICAL quoted by BRITISH MAEDICAL JoURNAL, FP
SEVENTY-NINTH ANNUAL MEETING

\section{通ritisly Atrdiral Azzoriation.}

Held in Birwingham on July 21st, 22nd, 24th, 25th, 26th, 27 th, and $28 t h$.

PROCEEDINGS OF SECTIONS.

\section{SECTION OF THERAPEUTICS, INCLUDING DIETETICS.}

Sir Robert M. Simon, M.D., F.R.C.P., Presidert.

\section{PRESIDENT'S OPENING REMARKS.}

THE first meeting of this Section was held in conjunction with that of Anatomy and Physiology, the object in view being a joint discussion on the merits of a low protein diet. Consequently. Sir Robert Simon, the President of the Section of Therapeutics, contented himself with extending a hearty welcome to all present, and more especially to those who were the guests of the Association, and then called upon Professor Chittenden to open the discussion.

\section{DISCUSSION ON}

\section{THE MERITS OF A RELATIVELY LOW PROTEIN DIET.}

\section{OPENING PAPER.}

By Dr. Russell H. Chittenden, Yale University, Newhaven, Connecticut.

The final justification of all scientific research, whether in the field of pure abstruse science or in the domain of applied science, is unquestionably the power it creates for the service of mankind, but before this power can be utilized it must be created. There must be definite knowledge, concise and accurate, before broad generalization and practical application can be hoped for. The methods of science are characterized by precision, by accuracy, as distinguished from the ordinary everyday methods of life. It is relatively easy to form opinions based mainly upon general impressions, upon evidence lacking in scientific accuracy, but opinions originating in this manner are very prone to be unreliable. They certainly lack the power of convincing the critical mind, thus differing from the opinions based upon the testimony of trustworthy observations. No matter how sceptical the attitude of mind, a careful record of accurate data in any branch of science is sure to gain the respectful attention of thoughtful people, because it represents detailed evidence of a definite character.

I am prompted to make these somewhat general statements because of the desire to emphasize the view that dietetics, as a part of the physiology of nutrition; is entitled to the same careful study as any other branch of biological science, and that the opinions and theories connected therewith should be formulated upon evidence that is both comprehensive and reliable. I know of no reason why the scientific method, with its highest attainable accuracy, should not be applied to the study of the amount and character of the daily food required by man; yet there seems to exist in many quarters at least a strong sentiment that "the orthodox physiological faith" must not under any circumstances be interfered with. This faith is based mainly upon general impressions, which in turn are predicated upon the everyday practices of mankind. In nearly every civilized country careful study has been made of the character and quantity of the food eaten by different classes of people, of different ages, sex, and body weight, and under diverse conditions of season, climate, and occupation. From the thousands of observations so made certain general conclusions have been drawn regarding the requirements of the body for food. Certain dietary standards have been adopted, which have 